Published in final edited form as:

J Midwifery Womens Health. 2015 ; 60(2): 146-225. doi:10.1111/jmwh.12236.

\title{
Primary Care of Women Aging with HIV
}

Julie A. Womack, CNM, APRN, PhD,

Assistant Professor at the Yale School of Nursing and is in clinical practice at the Nathan Smith Clinic in New Haven, CT

Cynthia A. Brandt, MD, MPH, and

Professor at the Yale School of Medicine in New Haven, CT, and is Director of the Veterans Health Administration Informatics Fellowship in West Haven, CT

Amy C. Justice, MD, PhD

Professor at the Yale School of Medicine in New Haven, CT, and is the Principle Investigator for the Veterans Aging Cohort Study

\section{Abstract}

Women are living longer with HIV infection, but their life expectancy is shorter than for women in the general population. How best to manage the multiple comorbidities and polypharmacy that are common in HIV infected individuals has not been studied.

This paper explores areas where the primary care of women with HIV may differ from that of aging women in the general population. We also discuss aspects of care that may not commonly be considered in those under the age of 65 , specifically multimorbidity and polypharmacy.

Incorporating a gerontologic approach in the care of these women may optimize outcomes until research provides more definitive answers as to how best to collaborate with women with HIV to provide them with optimal care.

\section{Keywords}

HIV; aging; polypharmacy; multimorbidity; primary care

\section{INTRODUCTION}

Since the advent of antiretroviral therapy (ART), HIV infection has become a chronic disease, managed with medications that have ever-increasing efficacy and decreased toxicity. This has resulted in the aging of the HIV epidemic: by 2015 , more than $50 \%$ of individuals with HIV in the United States will be over the age of 50. In the current treatment era, conditions that are not AIDS-associated, such as cardiovascular disease, diabetes, substance abuse, and depression, drive morbidity and mortality among individuals with HIV, and health care visits focus on primary care rather than HIV-specific care. ${ }^{1}$ Thus, a number of

Corresponding author: Julie A. Womack, Yale School of Nursing, PO Box 27399, West Haven, CT, 06516-7399, Telephone: 203-932-5711 x 4224, Fax: 203-937-4926, Julie.womack@yale.edu.

Conflict of Interest: The authors have no conflicts of interest to disclose. 
experts suggest that primary care (rather than specialty HIV) clinics should be the healthcare home for individuals living with HIV, as it is for individuals living with other chronic illnesses. More primary care providers, including midwives and nurse practitioners, will be needed to provide primary care to these patients, particularly as they age.

Guidelines for HIV primary care have multiplied, providing numerous sources of guidance on topics such as diagnosis and management of dyslipidemia, decreased bone mineral density, and cervical cancer screening. Recently, the Infectious Disease Society of America published a comprehensive guide to HIV primary care, addressing both HIV-specific and general primary care concerns for patients living with HIV. ${ }^{2}$ These guidelines, however, do not address certain issues that are of key importance to women, such as anemia, nor do they address issues of growing importance to all individuals aging with HIV such as multimorbidity (the co-existence of two or more long-term conditions in an individual) and polypharmacy (the use of five or more medications, including prescribed, over-the-counter, and complementary).

Multimorbidity and polypharmacy are traditionally associated with the elderly, and providers are accustomed to thinking of the elderly as being over the age of 65 . However, among HIV-infected individuals, those 50 years of age and older are considered elderly. This terminology reflects that even with ART, HIV-infected individuals do not have a normal lifespan. Preliminary estimates suggest that women infected with HIV may lose 13 to 16 years of life compared to their uninfected counterparts (Table 1), three years more than HIVinfected men lose relative to uninfected men. ${ }^{3}$ It is not yet clear what implications this shortened lifespan, or women's survival disadvantage relative to men, should have for patient care, but incorporating gerontologic principles into the care that we provide for our older HIV-infected patients may be a useful approach.

This review will address routine primary care issues that women's health care providers will encounter with their older patients with HIV, focusing on areas where care differs from that of women in the general population, younger women with HIV, and from men with HIV. For example, recommendations for screening for sexually transmitted infections, including hepatitis B virus infection, will not be reviewed in detail as they are not specific to older women. In addition, the limitations of individual guidelines for patients with multiple chronic diseases will be discussed. Recommendations are discussed at length in the text and are summarized with references in Table 2.

\section{MENOPAUSE}

Women in the United States who are HIV-infected have a number of risk factors for early menopause, including black race, lower body mass index, smoking, stress, less education, methadone use, illicit substance use (particularly opiates and cocaine) and use of psychotropic drugs. ${ }^{4}$ However, when compared to demographically similar uninfected women, those with HIV do not experience menopause at an earlier age. ${ }^{5}$ There is a high prevalence of menstrual irregularities among women living with HIV, secondary to illicit substance abuse; medications including psychotropics, narcotics, methadone, or corticosteroids; and comorbid conditions including diabetes, kidney disease, or liver 
disease. ${ }^{6,7}$ This makes the diagnosis of menopause challenging. In this population, rather than relying solely on 12 months of amenorrhea, providers might wish to assess timed serum follicle-stimulating hormone (FSH) and estradiol concentrations to confirm or disprove ovarian failure as the source of the amenorrhea. ${ }^{8}$ Particularly for a woman in her very early 50s who has HIV, pregnancy must be considered when she presents with amenorrhea.

Recent guidelines recommend against the use of hormone replacement therapy (HRT) for disease prevention among women with $\mathrm{HIV},{ }^{2}$ as is true for the general population of women. There is evidence, however, that these women experience more, and more severe, menopausal symptoms than their uninfected counterparts, thus supporting the use of HRT for symptom management. ${ }^{4}$

Hot flashes, night sweats in particular, need to be differentiated from HIV-associated conditions. ${ }^{4}$ While a common experience for postmenopausal women, night sweats could also be a marker for tuberculosis or non-Hodgkins lymphoma. Evaluation should include a careful history for possible exposure to tuberculosis, and testing to rule out tuberculosis using a QuantiFERON test or the purified protein derivative (PPD) tuberculin skin test. Note that a reaction $\geq 5 \mathrm{~mm}$ of induration indicates tuberculin positivity for HIV infected individuals. ${ }^{9}$ Physical and laboratory examinations assessing for fever, weight loss, a rapidly growing mass, hepatomegaly, splenomegaly, cytopenias, current CD4 count and HIV-RNA, may be indicated as well, depending on the woman's history.

Women may also experience memory loss during or after menopause. Among women with HIV, providers should be aware that memory loss could also be related to HIV infection, particularly if the HIV viral load is elevated. This topic will be developed further in the "Mental Health/Neurology" section of this paper.

Once alternative etiologies have been ruled out, symptomatic treatment should be considered. Hormone replacement therapy at the lowest effective dose for the shortest period of time is a reasonable approach. ${ }^{2,4}$ However, ART often interacts with estrogen and progestins, although the hormones likely do not interfere with the metabolism of ART. Most of this research has focused on hormonal contraception and ART. For example, protease inhibitor-based regimens that include ritonavir (the vast majority of protease inhibitor-based regimens) typically cause a reduction in ethinyl estradiol area under the curve and may decrease efficacy. ${ }^{10}$ Similar interaction may also result in decreased progestin concentrations. Alternative formulations, such as the patch, demonstrate similar outcomes. ${ }^{11}$ However, as the formulations and doses of hormones used differ between hormonal contraception and hormone replacement therapy, identical interactions cannot be assumed. Therefore, focusing on resolution of menopausal symptoms is key to determining appropriate dosing, and women with HIV who are on ART may require higher doses of estrogen and progestin than other women to achieve similar relief. Checking medication interactions on the AIDSinfo website (Table 3) is always indicated for the most up-to-date information.

A number of alternatives exist for addressing menopausal symptoms; these may also provide additional benefits. For example, selective serotonin reuptake inhibitors such as fluoxetine, 
and venlafaxine, a serotonin and norepinephrine reuptake inhibitor, have been shown to reduce the absolute risk of hot flashes by $19-60 \% .{ }^{12,13}$ Gabapentin (titrated to $2400 \mathrm{mg}$ over 12 days) has also shown efficacy on par with that of estrogen in treating moderate to severe hot flashes. ${ }^{14}$ High rates of depression and peripheral neuropathy among individuals living with HIV may make one of these options attractive, as one medication could be used to treat more than one condition.

\section{MENTAL HEALTH/NEUROLOGY Depression}

Individuals with HIV experience depressive symptoms at a rate of 2-4 times that of the general population. ${ }^{15}$ Whether or not women with HIV experience higher rates of depression than men is open to debate; some studies report higher rates in women ${ }^{16}$ while others do not. ${ }^{17}$ However the connection between depression and poor outcomes among individuals with HIV, and the improvement seen with treatment of depression, is clear, at least in part due to the improved adherence that is seen when depression is adequately treated. ${ }^{18}$

Older women with HIV may be at particular risk for depression associated with HIV-related stigma and loneliness. ${ }^{19}$ Women of color who are HIV-infected may be at particular risk. ${ }^{20}$ Why this is the case is not clear, but attitudes towards race and gender, as well as socioeconomic status, need to be considered when screening for and addressing stigma and depression in these populations.

Screening, diagnosis, and treatment of depression are thus key among older women with HIV. The New York State Department of Health (Table 3) suggests screening for depression at baseline and ongoing assessment at every visit. ${ }^{21}$

\section{Substance abuse}

The prevalence of alcohol use in the HIV-infected population may be as high as twice that found in the general population. ${ }^{22}$ The prevalence of illicit substance use among individuals with HIV was $81 \%$ in 2009, and at least $25 \%$ of those with HIV were in need of treatment for alcohol or illicit drug abuse in the same year. ${ }^{23}$ Substance use, particularly alcohol and illicit substance abuse, are associated with poor adherence to $\mathrm{ART}^{24}$ and risky sexual behavior, which may increase the risk of HIV transmission. ${ }^{25}$ Furthermore, substance abuse is associated with higher mortality among individuals with HIV, perhaps in part because substance use can decrease CD4 count. ${ }^{26}$ In the general population, hepatic consequences of alcohol abuse are more pronounced in women than in men, and women may be more susceptible to alcohol-induced brain damage than men. ${ }^{27,28}$ Women with HIV are also more likely than men to experience negative outcomes of substance use, including lower rates of adherence to antiretroviral therapy. ${ }^{29}$ Therefore, screening for alcohol and substance abuse is indicated at baseline and at least annually so that patients who have problems with substance abuse can be linked with treatment programs. 


\section{Cognitive impairment}

As yet, no gender differences have been identified for HIV-associated dementia. ${ }^{30}$ However, as most of the women in these studies are premenopausal, little is known about cognitive decline among postmenopausal women with HIV. ${ }^{31}$

Among older individuals with HIV, 68\% have reported some degree of cognitive impairment. Causes are doubtless multifactorial and include HIV-specific risk factors including low nadir CD4+ lymphocyte count and perhaps the use of antiretroviral regimens with poor central nervous system penetration, as well as those found in the general population, including older age, chronic HCV co-infection, polypharmacy, and frailty, and, perhaps, the use of antiretroviral regimens with poor central nervous system penetration. ${ }^{32}$ However, uncontrolled HIV is the most important risk factor for HIV-associated dementia. Thus being sure that patients have initiated ART and are adherent is of key importance. ${ }^{32}$

Persons with HIV may be cognitively impaired for reasons other than HIV infection; for example they may also have Alzheimer's disease as well as vascular dementias. A full workup to identify the cause of the dementia, including MRI of the brain and neuropsychological testing, is indicated, particularly among people on ART with fully suppressed HIV-RNA.

\section{CANCER}

\section{Cervical cancer}

The incidence of AIDS-defining cancers, including cervical cancer, has declined three-fold between 1995 and 2005. ${ }^{33}$ Women with HIV should be screened for cervical cancer when diagnosed with HIV, again six months later, and then annually if these initial tests are negative. ${ }^{2,34}$ There are, as yet, no guidelines for discontinuing cervical cancer screening among women over the age of 65 who are HIV infected, or among those who have had a hysterectomy unrelated to abnormal cervical cytology.

There are no guidelines that address human papilloma virus (HPV) screening for older women with HIV. Keller and colleagues found that the five-year cumulative incidence of high-grade squamous intraepithelial lesions (HSIL) or grade 2 or higher cervical intraepithelial neoplasia (CIN2+) was similar in women with HIV and their uninfected counterparts who were cytologically normal and oncogenic HPV-negative at baseline. ${ }^{35}$ However, the mean age of women in this study was 34 , and studies need to be done exploring HPV screening in older women with HIV.

\section{Anal cancer}

Rates of anal cancer are much higher among women with HIV compared with those who are uninfected. ${ }^{36}$ There is also more than a four-fold increased risk for having concomitant (anus and cervix) oncogenic HPV infection comparing women with HIV with uninfected women. ${ }^{8}$ Both oncogenic and nononcogenic HPV types were more prevalent in the anus than in the cervix in women with HIV. Use of ART has not been associated with a decreased risk of concomitant HPV infection. ${ }^{36}$ Among women with HIV, those with a CD4 count less than 
200 cells $/ \mu \mathrm{L}$ were more likely to have detectable oncogenic and nononcogenic HPV types in both the cervix and anus than those with higher CD4 counts. ${ }^{36}$

The recent HIV primary care guidelines from the Infectious Disease Society of America ${ }^{2}$ recommend anal pap smears for women with HIV who have a history of anal receptive intercourse, or who have had abnormal cervical cytology or anogenital warts. This is a weak recommendation with moderate quality evidence. Other organization-based guidelines do not recommend anal cancer screening for women with HIV. ${ }^{37}$ Opinions against routine screening typically focus on the lack of evidence that screening programs reduce the morbidity and mortality associated with anal cancer, and that there are few trials that have evaluated the efficacy and safety of current treatment modalities for precancerous anal lesions, particularly regarding complications or side effects of treatment. ${ }^{37}$

\section{CARDIOVASCULAR DISEASE AND METABOLIC DISORDERS}

\section{Cardiovascular disease}

Rates of cardiovascular disease are higher among women with HIV compared with uninfected women. ${ }^{38}$ While higher rates are, in part, associated with greater prevalence of Framingham risk factors (smoking, hypertension, and dyslipidemia), HIV infection does appear to be an independent risk factor for cardiovascular disease. ${ }^{38,39}$ Mechanisms that drive the association between HIV infection and cardiovascular disease remain to be elucidated but may include inflammation, CD4 cell count depletion, hypercoagulability, dyslipidemia, altered arterial elasticity, and endothelial dysfunction. Cardiovascular disease is known to be an inflammatory disease. ${ }^{40} \mathrm{HIV}$ is an important cause of inflammation even with fully suppressed virus, although mechanisms and pathways for this inflammation are not well understood. These may include ongoing viral replication and/or microbial translocation from the gut into surrounding tissues and blood. ${ }^{41}$ Antiretroviral therapy may also contribute to increased cardiovascular risk through associated metabolic changes and alterations in fat distribution such as lipodystrophy. However, the SMART study highlights the predominant contribution of HIV over ART. ${ }^{39}$ Briefly, the SMART study was designed to compare continuous treatment on antiretroviral therapy to CD4 count-guided scheduled treatment interruptions. This study conclusively demonstrated that intermittent treatment, compared with continuous antiretroviral treatment, was associated with increased risks of HIV disease progression and death, serious HIV disease progression, and severe complications. In particular, despite greater exposure to antiretroviral therapy, cardiovascular complications were less common in the continuous treatment group than in the intermittent treatment group. ${ }^{42}$

Possibly because of this independent effect of HIV, the Framingham risk calculator may underestimate the true cardiovascular disease risk in this population. However, as many of the Framingham risk factors are modifiable, particular attention should be paid to reducing these risk factors among women with HIV. As noted earlier, smoking is endemic in the HIVinfected population. Each point of contact with a provider should be an opportunity for assessing readiness to quit smoking and to provide counseling regarding smoking cessation and aids that can facilitate quitting. 
Because of heightened concern about long-term cardiovascular disease morbidity and mortality in this population, new primary care guidelines from the Infectious Disease Society of America ${ }^{2}$ suggest that a fasting lipid profile, fasting blood sugar, and hemoglobin A1c be done at initiation of HIV care, ${ }^{2}$ prior to initiation of ART, and within 1-3 months after starting ART. ${ }^{2}$ Metabolic abnormalities among individuals with HIV are common, resulting from a number of different factors including: direct effects of HIV itself, toxicities of ART, body composition changes, restoration to health, as well as traditional risk factors found in the general population. While increased LDL appears to be the result of restoration to health, hypertriglyceridemia and reduced HDL cholesterol are likely linked to direct effect of the virus. ${ }^{43}$ Specific antiretroviral medications have also been associated with dyslipidemia, specifically full-dose ritonavir, ritonavir-boosted regimens (ritonavir plus lopinavir or tipranavir or fosamprenavir), efavirenz, and stavudine. Ritonavir-boosted regimens also may decrease HDL concentrations. ${ }^{43}$ Indinavir transiently blocks the glucose transporter GLUT4 which results in elevated serum blood glucose levels. ${ }^{8}$ The nucleoside reverse transcriptase inhibitors such as zidovudine, stavudine, and didanosine, through their impact on mitochondrial toxicity, may contribute to insulin resistance. ${ }^{44}$ There are too few data on the newer drugs and classes of ART to draw conclusions about their effects on metabolism.

Blood pressure should be checked annually in all patients. ${ }^{2}$ Subsequent management should follow guidelines established for the general population.

A key concern among individuals on ART is the potential for pharmacokinetic interactions between medications used to treat comorbid conditions and protease inhibitors and nonnucleoside reverse transcriptase inhibitors, two of the most commonly used classes of ART. Lipid-lowering medications, especially statins, are of particular concern. Protease inhibitors inhibit metabolism of statins, thus increasing the potential for statin toxicity. Pitavastatin and pravastatin are exceptions as they are metabolized through glucuronidation, and can be used safely with protease inhibitors. ${ }^{8}$ Atorvastatin and rosuvastatin may also be used in patients taking protease inhibitors, but the initial dose should be low with careful titration to achieve the desired effect without toxicity. Cobicistat, one of the ingredients in a new single pill antiretroviral therapy (commonly called the "quad pill") likely interacts with statins in a manner similar to protease inhibitors, but this has not been well-explored. Efavirenz, a nonnucleoside reverse transcriptase inhibitor, induces statin metabolism, resulting in lower statin levels. Careful review of package inserts prior to prescribing lipid lowering medications is always indicated to rule out potential interactions.

Dihydropyridine calcium channel blockers can also be problematic. All protease inhibitors can increase levels of these medications, thus they should be used with caution. In particular, electrocardiogram (ECG) monitoring is recommended when a calcium channel blocker is used with atazanavir. ${ }^{10}$

\section{Osteoporosis}

Osteoporosis is more common among individuals with HIV compared with uninfected individuals ${ }^{45,46}$ as are fragility fractures. ${ }^{47}$ However there is little agreement regarding the primary risk factors for fractures in this population. Some authors have focused on the 
contribution of traditional risk factors found in the general population, including increasing age, white race, alcohol use, liver disease, corticosteroid use, current or past smoking, proton pump inhibitor use, body mass index, and decreased hemoglobin. ${ }^{47,48}$ Others have focused more on the contribution of HIV-specific factors, particularly tenofovir use and protease inhibitor use. ${ }^{49}$ Mundy and colleagues, however, have recently demonstrated an overall decreased fracture risk for individuals with HIV who are on ART, compared with those who are not. ${ }^{50}$ Drug-specific risk estimates for fracture demonstrated an increased risk for fracture with darunavir (adjusted odds ratio [aOR] 1.93, 95\% confidence interval [CI] 1.05, 3.56). These results are consistent with other studies pointing to a possible association between protease inhibitors and fracture risk. ${ }^{50}$ Likely, all of these factors, traditional risk factors, HIV and ART, contribute to the risk of osteoporosis in this population.

Recent guidelines ${ }^{2}$ suggest that osteoporosis screening include a baseline bone densitometry for all postmenopausal women. However, as T-scores are diagnostic thresholds for osteoporosis and osteopenia only, ${ }^{51}$ pharmacologic intervention should be based on absolute fracture risk that includes clinical fragility fracture risk factors. An algorithm most commonly used to calculate fracture risk (FRAX) (Table 3) integrates clinical risk factors for fractures with bone mineral density at the femoral neck to determine the 10-year probability of both hip and major osteoporotic fracture (clinical spine, forearm, hip or shoulder fracture)..$^{51}$

\section{ANEMIA}

Anemia has been an important concern for individuals infected with HIV since the early years of the epidemic when it was typically severe and driven by direct effects on the bone marrow of HIV, opportunistic infections, and zidovudine. ${ }^{52}$ Currently, ART is associated with resolution of and protection against anemia. Nonetheless, $30 \%$ of individuals with HIV are anemic. ${ }^{53}$ This anemia is usually mild, although it is associated with decreased survival. The SMART study ${ }^{53}$ explored the relationship between anemia and death in approximately 2000 individuals with HIV, 28\% of whom were women. Anemia was defined as less than 12 $\mathrm{g} / \mathrm{dL}$ in women and less than 14 in men. Over the five years of follow-up, those who were anemic had more than twice the risk of death as those who were not (adjusted relative risk 2.31; 95\% CI, 1.34-3.98). There were 0.54 deaths per 100 person years of follow-up in the group with normal hemoglobin, and 1.95 deaths per 100 person years of follow-up in the anemic group.

Pathogenesis of HIV-related anemia is multifactorial but may be driven by persistent inflammation, although all routine causes of anemia should be ruled out. Women, blacks, intravenous drug users, and older individuals are at greatest risk for anemia. ${ }^{54}$

In the elderly general population, anemia is also associated with decreased survival, impaired functional status and poor quality of life. It is associated with reduced physical performance, fatigue, functional dependence, disability, declining muscle strength and density, declining executive function and cognitive impairment (particularly in older women), and an increased risk of falls and frailty. These outcomes require further exploration in the HIV-infected population. 


\section{CO-INFECTION WITH HEPATITIS C VIRUS}

In the United States, one-quarter of people living with HIV are co-infected with hepatitis C virus (HCV). ${ }^{55}$ Given the "age wave" of chronic HCV seen in baby boomers, ${ }^{56}$ it is particularly important for older individuals newly diagnosed with HIV to also be assessed for HCV. Annual testing should continue for those at risk, including those with ongoing injection drug use, and chronic hemodialysis. ${ }^{2}$ Those who test positive for HCV antibodies should have a confirmatory test using a sensitive quantitative assay to measure plasma $\mathrm{HCV}$ RNA. ${ }^{2}$ Those who are HCV seropositive and not immune to or infected with hepatitis B should be vaccinated. Those without immunity to hepatitis A should also be vaccinated. Counselling regarding cessation of alcohol use is also of central importance.

Recent advances in treatment for HCV have improved so dramatically that all coinfected patients should be referred to an experienced specialist for treatment. Watchful waiting to determine the need for treatment is no longer appropriate. Patients who abuse intravenous substances should be educated about safer injection practices and encouraged to stop using altogether as post-treatment reinfection with hepatitis $\mathrm{C}$ is possible. ${ }^{8}$

All individuals with HCV should be cautioned about use or overuse of medications that could be harmful to the liver, thus exacerbating the risk of liver damage. Acetaminophen use is of particular concern. ${ }^{8}$ Providers should also ask about all over-the-counter or alternative therapies so that their impact on the liver can be reviewed.

\section{IMMUNIZATIONS}

Women with HIV are eligible for all routine immunizations recommended by the Centers for Disease Control and Prevention, on the same schedule as their uninfected counterparts, with one exception: live virus vaccines are contraindicated in individuals with CD4 counts less than 200 cells/ $\mu \mathrm{L} .^{2,57}$ Varicella and measles-mumps-rubella vaccines (MMR) are recommended as in uninfected individuals when CD4 counts are above 200 cells $/ \mu \mathrm{L}^{57}$.

The zoster vaccine, (Zostavax, Merck \& Co., Inc, Whitehouse Station, New Jersey), is more problematic: there are as yet only minimal data suggesting that the zoster vaccine is safe and effective for individuals with HIV who have CD4 counts $>200$ cells $/ \mu \mathrm{L}$. An AIDS Clinical Trial Group study explored the safety and efficacy of the zoster vaccine among individuals with HIV who had fully suppressed HIV-RNA, were on ART, had CD4 cell counts greater than 200 cells $/ \mu \mathrm{L}$, and had positive baseline varicella titers. This study measured varicella zoster virus (VZV) antibody titers at six and 12 weeks post-immunization and found that the participants who received the zoster vaccine had significantly higher varicella titers than those who did not. Investigators had decided a priori that use of the zoster vaccine would be considered safe if no more than 18 of the 295 (6.1\%) people receiving the vaccine experienced a severe side effect. While the severe adverse events were not described in the study, prior research has identified asthma exacerbations, polymyalgia rheumatica, anaphylaxis and Goodpasture's Syndrome as possible post-vaccine complications. ${ }^{58}$ Seventeen of the patients (5\%) in the zoster vaccine group met this endpoint compared to 2 $(2.1 \%)$ of the 97 patients in the placebo group. The difference was not statistically 
significant, and the authors concluded that two doses of the zoster vaccine were "generally safe" in the individuals with HIV who met inclusion criteria. ${ }^{59}$

The Advisory Committee on Immunization Practices and the Infectious Disease Society of America do not recommend for or against use of the zoster vaccine in patients with HIV who have CD 4 counts greater than 200 cells $/ \mu \mathrm{L}$. And yet, vaccinating individuals with HIV against zoster, if the vaccine is safe and effective, may provide significant benefit, given the high prevalence of zoster and associated high rates of complications, both acute neuralgia and post-herpetic neuralgia, in this population ${ }^{60}$ even in the ART era. ${ }^{61}$

Because the concentration of attenuated varicella virus is 14 times higher in the zoster vaccine than in the chicken pox vaccine (Varivax, Merck \& Co., Inc, Whitehouse Station, New Jersey) ${ }^{62}$ it is generally agreed that checking for antibodies to varicella virus prior to vaccinating with the zoster vaccine is important, as individuals who are varicella virus seronegative should be vaccinated with the varicella, not the zoster, vaccine. ${ }^{58}$

Given these complexities, primary care providers caring for women with HIV over the age of 60 who have with CD4 counts well over 200 cells/ $\mu \mathrm{L}$, fully suppressed viral loads, and evidence of exposure to chickenpox, might consider consulting with the patient's HIV provider to discuss immunization with the zoster vaccine and optimal treatment should the vaccine result in symptomatic zoster. If HIV-RNA is detectable, if an individual is not on ART, or if the CD4 count is lower than or quite close to 200 cells $/ \mu \mathrm{L}$, immunization should be deferred.

\section{MULTIMORBIDITY AND POLYPHARMACY}

The high prevalence of multimorbidity among individuals with HIV has been well documented. ${ }^{63}$ Multimorbidity may be related to HIV itself, to immunosuppression, to antiretroviral medications, and/or to an increased prevalence of traditional risk factors among individuals with HIV. Salter and colleagues ${ }^{63}$ found that the risk of multimorbidity in this population increased with advanced immunosuppression and HIV viremia. Their study addressed seven non-AIDS defining chronic diseases: diabetes, obstructive lung disease, liver disease, anemia, obesity, kidney dysfunction and hypertension. In contrast, Kim and colleagues $^{64}$ found that obesity was associated with a higher likelihood of multimorbidity among individuals with HIV. While little is known about multimorbidity among women with HIV, Salter and colleagues ${ }^{63}$ suggest that women with HIV may be more likely to experience multimorbidity than men with HIV, although why this may be the case is not yet understood.

In the general population, multimorbidity is associated with decreased functional status and quality of life, increased adverse drug events, medical costs, disability, and mortality. ${ }^{65}$ These outcomes have not been explored among individuals with HIV, but are likely similar. ${ }^{66}$

Polypharmacy may contribute to morbidity and mortality through its association with nonadherence, the presence of pre-existing organ system injury that may be aggravated by the toxicity from additional medications, drug-drug interactions, and ongoing substance use. ${ }^{67}$ 
Polypharmacy has been associated with poor health outcomes including hospitalization and mortality in the general population, ${ }^{68}$ but until recently has received little attention in the context of HIV. In the Veterans Aging Cohort Study, 55\% of individuals with HIV who were over the age of 50 took five or more daily medications. ${ }^{67}$ Women in the general population typically experience a higher prevalence of polypharmacy than men, ${ }^{68}$ possibly because women visit health care providers more often than men ${ }^{69}$ although this difference may resolve with increasing age. Patterns of polypharmacy are as yet unexplored in HIV-infected populations.

\section{CONCLUSION}

Guideline-based care presents particular challenges. Most practice guidelines target a single, index condition. Aberg and colleagues present at least 13 different guidelines that should be considered when managing the care of older women with HIV. This focus on single-disease guidelines may result in treatment plans that are inefficient, ineffective, and potentially harmful to patients. ${ }^{65,70} \mathrm{Few}$ guidelines exist to help primary care providers manage and prevent chronic disease in these complex patients, as most clinical trials exclude those with multimorbidity, particularly those with HIV infection.

Management of multimorbidity should include understanding and incorporating patient preferences, shifting priorities and healthcare goals into the care plan. This should involve discussions with patients around their priorities, reviewing their current plan of care, and their ability to adhere to the current plan. Providers then need to consider the patient's preferences in the context of relevant evidence that supports the achievement of these outcomes. Interactions within and among treatments and conditions should be considered, and providers should weigh benefits and harms of components of the treatment plan with the patient. ${ }^{71}$ Ideally, this discussion would take place with the specialty providers and the patient, together with the primary care provider. This level of collaboration is difficult to achieve in our health care system, thus primary care providers need to communicate with specialists, and patients need to be empowered to communicate their priorities to all of their providers along with any concerns that they may have regarding how specific treatments may interfere with these priorities.

Primary care of women with HIV is similar to that of women in the general population, but there are issues particular to HIV, the understanding of which can enhance the provision of quality care. These issues are summarized in Table 2 . An initial response to the complexity of care for women with HIV has been an increased number of guidelines and recommendations for what should be done to prevent undesired consequences. However, shortened life expectancy and the high prevalence of multimorbidity and polypharmacy make guideline-based care a difficult proposition. The dangers of using multiple singledisease guidelines for the care of patients with multimorbidity are well established. ${ }^{70}$ For example, in a patient with osteoarthritis and hypertension, non-steroidal anti-inflammatories are recommended to treat the osteoarthritis but may worsen the hypertension and decrease the efficacy of a diuretic if it is used. 
Providers need to talk with their patients to identify healthcare priorities so that treatment can be adjusted to enhance these outcomes. That patients' preferences change is welldocumented, so this conversation about goals for care needs to be ongoing, with changes to the care plan reflecting the evolution of preferences.

However, we do not understand how best to partner with patients to help them be advocates for themselves and their families. Including patients as full participants and decision-makers in their healthcare is important but difficult to implement: their healthcare is often so complex that even providers often do not fully understand the technicalities of every aspect of the patient's care. Understanding what self-management means in this context, and how to incorporate friends and family members into this process requires further research. Unfortunately, because of the persistent stigma associated with HIV infection, many patients may not have disclosed their HIV status even to their closest friends and family. How to provide care for these more isolated individuals is an important area of research and clinical concern.

\section{Acknowledgments}

This work was supported by: the Veterans Administration Office, Academic Affiliations, Information Research \& Development Medical Informatics Fellowship Program; The National Institute of Nursing Research of the National Institutes of Health: Grant number 1K01NR013437-01; National Center for Research Resources and the National Center for Advancing Translational Science, and Center for Advancing Translational Science, Components of the National Institutes of Health, and NIH roadmap for Medical Research: CTSA Grant Number UL1 RR024138, and the Veterans Aging Cohort Study funded by: National Institute on Alcohol Abuse and Alcoholism (U10 AA 13566) and VHA Public Health Strategic Health Core Group. The contents are solely the responsibility of the authors and do not necessarily represent the official view of NIH or the VA.

\section{References}

1. Hasse B, Ledergerber B, Furrer H, et al. Morbidity and aging in HIV-infected persons: the Swiss HIV cohort study. Clin Infect Dis. Dec; 2011 53(11):1130-1139. [PubMed: 21998280]

2. Aberg JA, Gallant JE, Ghanem KG, Emmanuel P, Zingman BS, Horberg MA. Primary Care Guidelines for the Management of Persons Infected With HIV: 2013 Update by the HIV Medicine Association of the Infectious Diseases Society of America. Clin Infect Dis. Jan; 2014 58(1):e1-e34. [PubMed: 24235263]

3. Antiretroviral Therapy Cohort C. Life expectancy of individuals on combination antiretroviral therapy in high-income countries: a collaborative analysis of 14 cohort studies. Lancet. Jul 26; 2008 372(9635):293-299. [PubMed: 18657708]

4. Cejtin HE. Care of the human immunodeficiency virus-infected menopausal woman. American journal of obstetrics and gynecology. Aug; 2012 207(2):87-93. [PubMed: 22284959]

5. Fantry LE, Zhan M, Taylor GH, Sill AM, Flaws JA. Age of menopause and menopausal symptoms in HIV-infected women. AIDS patient care and STDs. Nov; 2005 19(11):703-711. [PubMed: 16283830]

6. Cejtin HE, Kalinowski A, Bacchetti P, et al. Effects of human immunodeficiency virus on protracted amenorrhea and ovarian dysfunction. Obstetrics and gynecology. Dec; 2006 108(6):1423-1431. [PubMed: 17138776]

7. Massad LS, Evans CT, Minkoff H, et al. Effects of HIV infection and its treatment on self-reported menstrual abnormalities in women. Journal of women's health (2002). Jun; 2006 15(5):591-598.

8. Burdo TH, Lo J, Abbara S, et al. Soluble CD163, a novel marker of activated macrophages, is elevated and associated with noncalcified coronary plaque in HIV-infected patients. The Journal of infectious diseases. Oct 15; 2011 204(8):1227-1236. [PubMed: 21917896] 
9. Targeted tuberculin testing and treatment of latent tuberculosis infection. American Thoracic Society. MMWR. Recommendations and reports: Morbidity and mortality weekly report. Recommendations and reports/Centers for Disease Control. Jun 9; 2000 49(RR-6):1-51.

10. AIDSinfo. Guidelines for the USe of Antiretroviral Agents in HIV-1-Infected Adults and Adolescents. 2013. http://aidsinfo.nih.gov/guidelines/html/1/adult-and-adolescent-arvguidelines/0. Accessed 23 May 2013

11. Vogler MA, Patterson K, Kamemoto L, et al. Contraceptive efficacy of oral and transdermal hormones when co-administered with protease inhibitors in HIV-1-infected women: pharmacokinetic results of ACTG trial A5188. Journal of acquired immune deficiency syndromes (1999). Dec; 2010 55(4):473-482. [PubMed: 20842042]

12. Loprinzi CL, Sloan JA, Perez EA, et al. Phase III evaluation of fluoxetine for treatment of hot flashes. Journal of clinical oncology: official journal of the American Society of Clinical Oncology. Mar 15; 2002 20(6):1578-1583. [PubMed: 11896107]

13. Evans ML, Pritts E, Vittinghoff E, McClish K, Morgan KS, Jaffe RB. Management of postmenopausal hot flushes with venlafaxine hydrochloride: a randomized, controlled trial. Obstetrics and gynecology. Jan; 2005 105(1):161-166. [PubMed: 15625158]

14. Reddy SY, Warner H, Guttuso T Jr, et al. Gabapentin, estrogen, and placebo for treating hot flushes: a randomized controlled trial. Obstetrics and gynecology. Jul; 2006 108(1):41-48. [PubMed: 16816054]

15. Ciesla JA, Roberts JE. Meta-analysis of the relationship between HIV infection and risk for depressive disorders. Am J Psychiatry. May; 2001 158(5):725-730. [PubMed: 11329393]

16. Turner BJ, Laine C, Cosler L, Hauck WW. Relationship of gender, depression, and health care delivery with antiretroviral adherence in HIV-infected drug users. Journal of general internal medicine. Apr; 2003 18(4):248-257. [PubMed: 12709091]

17. Haug NA, Sorensen JL, Lollo ND, Gruber VA, Delucchi KL, Hall SM. Gender differences among HIV-positive methadone maintenance patients enrolled in a medication adherence trial. AIDS care. Nov; 2005 17(8):1022-1029. [PubMed: 16176898]

18. Hartzell JD, Janke IE, Weintrob AC. Impact of depression on HIV outcomes in the HAART era. The Journal of antimicrobial chemotherapy. Aug; 2008 62(2):246-255. [PubMed: 18456650]

19. Grov C, Golub SA, Parsons JT, Brennan M, Karpiak SE. Loneliness and HIV-related stigma explain depression among older HIV-positive adults. AIDS care. May; 2010 22(5):630-639. [PubMed: 20401765]

20. Loutfy MR, Logie CH, Zhang Y, et al. Gender and ethnicity differences in HIV-related stigma experienced by people living with HIV in Ontario, Canada. PloS one. 2012; 7(12):e48168. [PubMed: 23300514]

21. Health NYSDo

22. Galvan FH, Bing EG, Fleishman JA, et al. The prevalence of alcohol consumption and heavy drinking among people with HIV in the United States: results from the HIV Cost and Services Utilization Study. Journal of studies on alcohol. Mar; 2002 63(2):179-186. [PubMed: 12033694]

23. Substance Abuse and mental Health Services Administration CfBHSaQ. The NSDUH Report: HIV/AIDS and Substance Use. 2010

24. Hinkin CH, Hardy DJ, Mason KI, et al. Medication adherence in HIV-infected adults: effect of patient age, cognitive status, and substance abuse. AIDS (London, England). Jan 1; 2004 18(Suppl 1):S19-25.

25. Shoptaw SaFD. Substance abuse treatment as HIV prevention for men who have sex with men. AIDS and behavior. 2000; 4(2):193-203.

26. Ickovics JR, Hamburger ME, Vlahov D, et al. Mortality, CD4 cell count decline, and depressive symptoms among HIV-seropositive women: longitudinal analysis from the HIV Epidemiology Research Study. JAMA. Mar 21; 2001 285(11):1466-1474. [PubMed: 11255423]

27. Hahn JA, Samet JH. Alcohol and HIV disease progression: weighing the evidence. Current HIV/ AIDS reports. Nov; 2010 7(4):226-233. [PubMed: 20814765]

28. Brady KT, Randall CL. Gender differences in substance use disorders. The Psychiatric clinics of North America. Jun; 1999 22(2):241-252. [PubMed: 10385931] 
29. Spittal PM, Craib KJ, Wood E, et al. Risk factors for elevated HIV incidence rates among female injection drug users in Vancouver. CMAJ. Apr 2; 2002 166(7):894-899. [PubMed: 11949985]

30. Garrido JMF, Fernandez ML, Foltz M, Castro YR, Fernandez MVC. Cognitive performance in men and women infected with HIV-1. Psychiatry Journal. 2013:2013.

31. Maki PM, Martin-Thormeyer E. HIV, cognition and women. Neuropsychology review. Jun; 2009 19(2):204-214. [PubMed: 19430907]

32. Winston A, Arenas-Pinto A, Stohr W, et al. Neurocognitive function in HIV infected patients on antiretroviral therapy. PloS one. 2013; 8(4):e61949. [PubMed: 23646111]

33. Shiels MS, Pfeiffer RM, Gail MH, et al. Cancer burden in the HIV-infected population in the United States. Journal of the National Cancer Institute. May 4; 2011 103(9):753-762. [PubMed: 21483021]

34. Kaplan JE, Benson C, Holmes KK, et al. Guidelines for prevention and treatment of opportunistic infections in HIV-infected adults and adolescents: recommendations from CDC, the National Institutes of Health, and the HIV Medicine Association of the Infectious Diseases Society of America. MMWR. Recommendations and reports: Morbidity and mortality weekly report. Recommendations and reports/Centers for Disease Control. Apr 10; 2009 58(RR-4):1-207. quiz CE201-204.

35. Keller MJ, Burk RD, Xie X, et al. Risk of cervical precancer and cancer among HIV-infected women with normal cervical cytology and no evidence of oncogenic HPV infection. JAMA. Jul 25; 2012 308(4):362-369. [PubMed: 22820789]

36. Hessol NA, Holly EA, Efird JT, et al. Concomitant anal and cervical human papillomavirusV infections and intraepithelial neoplasia in HIV-infected and uninfected women. AIDS (London, England). Jul 17; 2013 27(11):1743-1751.

37. Asboe D, Aitken C, Boffito M, et al. British HIV Association guidelines for the routine investigation and monitoring of adult HIV-1-infected individuals 2011. HIV medicine. Jan; 2012 13(1):1-44. [PubMed: 22171742]

38. Triant VA, Lee H, Hadigan C, Grinspoon SK. Increased acute myocardial infarction rates and cardiovascular risk factors among patients with human immunodeficiency virus disease. The Journal of clinical endocrinology and metabolism. Jul; 2007 92(7):2506-2512. [PubMed: 17456578]

39. Freiberg MS, Chang CC, Kuller LH, et al. HIV infection and the risk of acute myocardial infarction. JAMA internal medicine. Apr 22; 2013 173(8):614-622. [PubMed: 23459863]

40. Ross R. Atherosclerosis-an inflammatory disease. The New England journal of medicine. Jan 14; 1999 340(2):115-126. [PubMed: 9887164]

41. Deeks SG. HIV infection, inflammation, immunosenescence, and aging. Annual review of medicine. 2011; 62:141-155.

42. El-Sadr WM, Lundgren JD, Neaton JD, et al. CD4+ count-guided interruption of antiretroviral treatment. The New England journal of medicine. Nov 30; 2006 355(22):2283-2296. [PubMed: 17135583]

43. Grunfeld C. Dyslipidemia and its Treatment in HIV Infection. Top HIV Med. Aug-Sep;2010 18(3): 112-118. [PubMed: 20921577]

44. Paik IJ, Kotler DP. The prevalence and pathogenesis of diabetes mellitus in treated HIV-infection. Best practice \& research. Clinical endocrinology \& metabolism. Jun; 2011 25(3):469-478. [PubMed: 21663840]

45. Brown TT, Qaqish RB. Antiretroviral therapy and the prevalence of osteopenia and osteoporosis: a meta-analytic review. AIDS (London, England). Nov 14; 2006 20(17):2165-2174.

46. Bolland MJ, Grey AB, Gamble GD, Reid IR. CLINICAL Review \#: low body weight mediates the relationship between HIV infection and low bone mineral density: a meta-analysis. The Journal of clinical endocrinology and metabolism. Dec; 2007 92(12):4522-4528. [PubMed: 17925333]

47. Womack JA, Goulet JL, Gibert C, et al. Increased Risk of Fragility Fractures among HIV Infected Compared to Uninfected Male Veterans. PloS one. 2011; 6(2):e17217. [PubMed: 21359191]

48. Womack JA, Goulet JL, Gibert C, et al. Physiologic Frailty and Fragility Fracture in HIV-Infected Male Veterans. Clin Infect Dis. May; 2013 56(10):1498-1504. [PubMed: 23378285] 
49. McComsey GA, Huang JS, Woolley IJ, et al. Fragility fractures in HIV-infected patients: need for better understanding of diagnosis and management. J Int Assoc Physicians AIDS Care (Chic Ill). Jul-Sep;2004 3(3):86-91.

50. Mundy LM, Youk AO, McComsey GA, Bowlin SJ. Overall benefit of antiretroviral treatment on the risk of fracture in HIV: nested case-control analysis in a health-insured population. AIDS (London, England). Jun 1; 2012 26(9):1073-1082.

51. Kanis JA, Johnell O, Oden A, Johansson H, McCloskey E. FRAX and the assessment of fracture probability in men and women from the UK. Osteoporos Int. Apr; 2008 19(4):385-397. [PubMed: 18292978]

52. Richman DD, Fischl MA, Grieco MH, et al. The toxicity of azidothymidine (AZT) in the treatment of patients with AIDS and AIDS-related complex. A double-blind, placebo-controlled trial. The New England journal of medicine. Jul 23; 1987 317(4):192-197. [PubMed: 3299090]

53. Mocroft A, Lifson AR, Touloumi G, et al. Haemoglobin and anaemia in the SMART study. Antiviral therapy. 2011; 16(3):329-337. [PubMed: 21555815]

54. Semba RD, Shah N, Klein RS, et al. Prevalence and cumulative incidence of and risk factors for anemia in a multicenter cohort study of human immunodeficiency virus-infected and -uninfected women. Clin Infect Dis. Jan 15; 2002 34(2):260-266. [PubMed: 11740716]

55. Lacombe K, Rockstroh J. HIV and viral hepatitis coinfections: advances and challenges. Gut. May; 2012 61(Suppl 1):i47-58. [PubMed: 22504919]

56. McHutchison JG, Bacon BR. Chronic hepatitis C: an age wave of disease burden. The American journal of managed care. Oct; 2005 11(10 Suppl):S286-295. quiz S307-211. [PubMed: 16232012]

57. Group AAIW, Bridges CB, Woods L, Coyne-Beasley T, Centers for Disease C, Prevention. Advisory Committee on Immunization Practices (ACIP) recommended immunization schedule for adults aged 19 years and older-United States, 2013. Morbidity and mortality weekly report. Surveillance summaries. Feb 1; 2013 62(Suppl 1):9-19.

58. Oxman MN, Levin MJ, Johnson GR, et al. A vaccine to prevent herpes zoster and postherpetic neuralgia in older adults. The New England journal of medicine. Jun 2; 2005 352(22):2271-2284. [PubMed: 15930418]

59. Benson, CAHL.; Andersen, JW.; Jiang, HJ.; Bozzolo, DR.; Annunziato, P.; Read, S.; Pollard, R.; Rusin, D.; Lennox, J. ZOSTAVAX is generally safe and immunogenic in HIV-Infected adults with CD4 counts > 200 cells/microliter virologically suppressed on antiretroviral therapy: results of a phase 2, randomized, double-blind, placebo-controlled trial (A5247). Paper presented at: Conference on Retroviruses and Opportunistic Infections; March 5-8, 2012; Seattle, Washington.

60. Engels EA, Rosenberg PS, Biggar RJ. Zoster incidence in human immunodeficiency virus-infected hemophiliacs and homosexual men, 1984-1997. District of Columbia Gay Cohort Study. Multicenter Hemophilia Cohort Study. The Journal of infectious diseases. Dec; 1999 180(6):17841789. [PubMed: 10558932]

61. Moanna A, Rimland D. Decreasing incidence of herpes zoster in the highly active antiretroviral therapy era. Clin Infect Dis. Jul; 2013 57(1):122-125. [PubMed: 23487391]

62. CDC. HIV Surveillance - Epidemiology of HIV Infection. 2013 Accessed 29 October, 2013.

63. Salter ML, Lau B, Go VF, Mehta SH, Kirk GD. HIV infection, immune suppression, and uncontrolled viremia are associated with increased multimorbidity among aging injection drug users. Clin Infect Dis. Dec; 2011 53(12):1256-1264. [PubMed: 21976463]

64. Kim DJ, Westfall AO, Chamot E, et al. Multimorbidity patterns in HIV-infected patients: the role of obesity in chronic disease clustering. Journal of acquired immune deficiency syndromes (1999). Dec 15; 2012 61(5):600-605. [PubMed: 23023101]

65. Tinetti ME, Fried TR, Boyd CM. Designing health care for the most common chronic conditionmultimorbidity. Jama. Jun 20; 2012 307(23):2493-2494. [PubMed: 22797447]

66. Oursler KK, Goulet JL, Crystal S, et al. Association of age and comorbidity with physical function in HIV-infected and uninfected patients: results from the veterans aging cohort study. AIDS patient care and STDs. Jan; 2011 25(1):13-20. [PubMed: 21214375]

67. Edelman EJGK, Glover J, McNicholl IR, Fiellin DA, Justice AC. The next therapeutic challenge in HIV: Polypharmacy. Drugs and Aging. 2013 In press. 
68. Jyrkka J, Enlund H, Korhonen MJ, Sulkava R, Hartikainen S. Patterns of drug use and factors associated with polypharmacy and excessive polypharmacy in elderly persons: results of the Kuopio 75+ study: a cross-sectional analysis. Drugs and Aging. 2009; 26(6):493-503. [PubMed: 19591524]

69. Venturini CD, Engroff P, Ely LS, et al. Gender differences, polypharmacy, and potential pharmacological interactions in the elderly. Clinics. 2011; 66(11):1867-1872. [PubMed: 22086515]

70. Boyd CM, Darer J, Boult C, Fried LP, Boult L, Wu AW. Clinical practice guidelines and quality of care for older patients with multiple comorbid diseases: implications for pay for performance. JAMA. Aug 10; 2005 294(6):716-724. [PubMed: 16091574]

71. Panel on Prevention of Falls in Older Persons AGSaBGS. Summary of the Updated American Geriatrics Society/British Geriatrics Society clinical practice guideline for prevention of falls in older persons. Journal of the American Geriatrics Society. Jan; 59(1):148-157. 


\section{Quick points}

- $\quad$ Women with HIV are aging, but their life expectancy is still shorter than that of their uninfected counterparts.

- $\quad$ Optimal management of women infected with HIV should take into consideration multimorbidity and polypharmacy, but no research exists to guide patients and providers.

- $\quad$ Providers and patients may benefit from incorporating a gerontology perspective in the primary care of aging women with HIV. 


\section{Table 1}

Life Expectancy for Men and Women in the General Population Compared with those who are HIV infected.

\begin{tabular}{|l|l|l|l|}
\hline General population (HIV-) & Men & Women & Difference in life expectancy \\
\hline A 20 year old will live to be (years) & 76 & 80 & Women live 4 years longer than men \\
\hline A 35 year old will live to be (years) & 77 & 81 & Women live 4 years longer than men \\
\hline HIV+ at ART initiation & & & \\
\hline A 20 year old will live to be (years, adjusted) & 63 & 64 & Women live 1 year longer than men \\
\hline A 35 year old will live to be (years, adjusted) & 67 & 68 & Women live 1 year longer than men \\
\hline Years of life lost for HIV infected individuals & & & \\
\hline 20 year old & 13 & 16 & HIV+ women lose, on average, 3 years of life more than men. \\
\hline 35 year old & 10 & 13 & HIV+ women lose, on average, 3 years of life more than men. \\
\hline
\end{tabular}


Table 2

Summary of primary care recommendations for women with HIV

\begin{tabular}{|c|c|c|c|}
\hline Aspects of care & $\begin{array}{l}\text { Recommendations for } \\
\text { women with HIV }\end{array}$ & $\begin{array}{l}\text { Differences from the } \\
\text { general population }\end{array}$ & Gender-specific issues \\
\hline \multicolumn{4}{|l|}{ Menopause $^{2,4}$} \\
\hline & $\begin{array}{l}\text { Similar to women in the } \\
\text { general population. }\end{array}$ & $\begin{array}{l}\text { HIV may be associated with } \\
\text { earlier onset of menopause. } \\
\text { May need more than } 12 \\
\text { months amenorrhea to } \\
\text { diagnose (for example, } \\
\text { serum FSH and estrogen } \\
\text { concentrations may be } \\
\text { helpful). Likely associated } \\
\text { with more severe symptoms. } \\
\text { HRT and non-hormonal } \\
\text { alternatives may be } \\
\text { considered. Effective dosing } \\
\text { of HRT may be higher than } \\
\text { in the general population } \\
\text { because of drug/drug } \\
\text { interactions. }\end{array}$ & NA \\
\hline \multicolumn{4}{|l|}{ Mental Health/Neurology } \\
\hline Depression $^{1820}$ & $\begin{array}{l}\text { Screening at diagnosis and } \\
\text { then at least annually. }\end{array}$ & $\begin{array}{l}\text { Rates of depression much } \\
\text { higher among women with } \\
\text { HIV than in the general } \\
\text { population }\end{array}$ & $\begin{array}{l}\text { Rates of depression twice as } \\
\text { high in women with HIV as in } \\
\text { men with HIV. Role of stigma } \\
\text { should be explored. }\end{array}$ \\
\hline Substance abuse $\mathrm{e}^{232728}$ & $\begin{array}{l}\text { Screen at baseline and at } \\
\text { least annually for both } \\
\text { alcohol and drug use/abuse. } \\
\text { Refer for treatment as } \\
\text { indicated. }\end{array}$ & $\begin{array}{l}\text { Increases risk of HIV } \\
\text { transmission. Also has direct } \\
\text { effect on the immune system: } \\
\text { lowers CD4 count. }\end{array}$ & $\begin{array}{l}\text { Hepatic consequences of } \\
\text { alcohol abuse more pronounced } \\
\text { in women than men, women } \\
\text { may be more susceptible to } \\
\text { alcohol-induced brain damage } \\
\text { than men. }\end{array}$ \\
\hline Cognitive impairment $t^{3031}$ & & $\begin{array}{l}\text { Untreated HIV is likely most } \\
\text { important HIV-related cause. } \\
\text { Rule out other causes found } \\
\text { in general population, } \\
\text { including Alzheimer's and } \\
\text { vascular dementias. }\end{array}$ & $\begin{array}{l}\text { As yet, no gender differences } \\
\text { have been identified for HIV- } \\
\text { associated dementia. However } \\
\text { most of the women in these } \\
\text { studies are premenopausal, thus } \\
\text { not much is known about } \\
\text { cognitive decline among } \\
\text { postmenopausal, HIV infected } \\
\text { women. }\end{array}$ \\
\hline \multicolumn{4}{|l|}{ Cancer } \\
\hline Cervical $^{3424}$ & $\begin{array}{l}\text { Cervical cancer screening at } \\
\text { diagnosis and again } 6 \\
\text { months later. If normal, } \\
\text { annual screening. }\end{array}$ & $\begin{array}{l}\text { No explicit guidelines } \\
\text { regarding incorporation of } \\
\text { co-testing (cytology and } \\
\text { HPV). }\end{array}$ & NA \\
\hline $\mathrm{Anal}^{2}$ & $\begin{array}{l}\text { Screen women with } \\
\text { abnormal cervical testing, } \\
\text { with history of anal- } \\
\text { receptive intercourse, and } \\
\text { with anogenital warts. }\end{array}$ & $\begin{array}{l}\text { Screening not recommended } \\
\text { for women in the general } \\
\text { population. }\end{array}$ & $\begin{array}{l}\text { High rates of anal cancer in } \\
\text { both HIV+ men-who-have-sex- } \\
\text { with-men and in women with } \\
\text { HIV }\end{array}$ \\
\hline \multicolumn{4}{|c|}{$\begin{array}{l}\text { Cardiovascular disease and metabolic } \\
\text { disorders }\end{array}$} \\
\hline Cardiovascular disease (CVD) $)^{2}$ & $\begin{array}{l}\text { See individual guidelines } \\
\text { below for hypertension, } \\
\text { dyslipidemia and diabetes. }\end{array}$ & $\begin{array}{l}\text { Framingham risk score likely } \\
\text { underestimates true CVD } \\
\text { risk, but addressing these } \\
\text { risk factors is a good place to } \\
\text { start. }\end{array}$ & $\begin{array}{l}\text { Current research indicates that } \\
\text { in terms of CVD risk in women } \\
\text { with HIV vs men, there are few } \\
\text { differences. However, the } \\
\text { numbers of women with HIV } \\
\text { who have with CVD are limited } \\
\text { (most cohorts are composed of } \\
\text { younger women), limiting our } \\
\text { knowledge on this point. }\end{array}$ \\
\hline
\end{tabular}




\begin{tabular}{|c|c|c|c|}
\hline Aspects of care & $\begin{array}{l}\text { Recommendations for } \\
\text { women with HIV }\end{array}$ & $\begin{array}{l}\text { Differences from the } \\
\text { general population }\end{array}$ & Gender-specific issues \\
\hline Hypertension $^{2}$ & $\begin{array}{l}\text { Annual screening. } \\
\text { Management same as in } \\
\text { general population. }\end{array}$ & $\begin{array}{l}\text { Be aware of possible drug/ } \\
\text { drug interactions. }\end{array}$ & None \\
\hline Dyslipidemia $^{2}$ & $\begin{array}{l}\text { Screen at initial visit, before } \\
\text { starting ART, and } 1-3 \\
\text { months after ART initiation. } \\
\text { Management is similar as in } \\
\text { the general population }\end{array}$ & $\begin{array}{l}\text { Be cognizant of drug-drug } \\
\text { interactions when } \\
\text { prescribing lipid-lowering } \\
\text { medications, particularly } \\
\text { statins with protease } \\
\text { inhibitors. }\end{array}$ & None \\
\hline Diabetes $^{2}$ & $\begin{array}{l}\text { Screen at initial visit, before } \\
\text { starting ART, and } 1-3 \\
\text { months after ART initiation. } \\
\text { Management the same as in } \\
\text { the general population. }\end{array}$ & $\begin{array}{l}\text { Rates of diabetes lower } \\
\text { among individuals with HIV } \\
\text { than among the general } \\
\text { population. }\end{array}$ & None \\
\hline Osteoporosis ${ }^{2}$ & $\begin{array}{l}\text { Baseline bone densitometry } \\
\text { on all post-menopausal } \\
\text { women. }\end{array}$ & $\begin{array}{l}\text { Baseline bone densitometry } \\
\text { on women } 65 \text { years of age or } \\
\text { older, thus much later than } \\
\text { among women with HIV. }\end{array}$ & $\begin{array}{l}\text { Recommendation that HIV+ } \\
\text { men receive routine screening } \\
\text { at age } 50 .\end{array}$ \\
\hline \multicolumn{4}{|l|}{ Anemia $^{2}$} \\
\hline & $\begin{array}{l}\text { CBC obtained at entry into } \\
\text { care. No HIV-specific } \\
\text { guidelines for definition or } \\
\text { management of anemia. }\end{array}$ & $\begin{array}{l}\text { Anemia more common } \\
\text { among women with HIV } \\
\text { than in the general } \\
\text { population and closely } \\
\text { associated with mortality } \\
\text { regardless of CD4 count. }\end{array}$ & $\begin{array}{l}\text { Anemia far more common in } \\
\text { women than men. }\end{array}$ \\
\hline \multicolumn{4}{|c|}{ Coinfection with Hepatitis $\mathrm{C}^{2}$} \\
\hline & $\begin{array}{l}\text { Test at entry into care and } \\
\text { annual testing if risk factors } \\
\text { persist. }\end{array}$ & $\begin{array}{l}\text { High rates in baby boom } \\
\text { generation add to the need } \\
\text { for screening in this age } \\
\text { group }\end{array}$ & None \\
\hline \multicolumn{4}{|l|}{ Immunizations } \\
\hline Zoster vaccine ${ }^{572}$ & $\begin{array}{l}\text { Do not use in individuals } \\
\text { with CD4 count at or below } \\
200 \text { cells } / \mu \mathrm{L} \text {. } \\
\text { No recommendation for or } \\
\text { against use in individuals } \\
\text { with CD4 > } 200 \text { cells } / \mu \mathrm{L} \text {. }\end{array}$ & $\begin{array}{l}\text { Uncertainty re safety and } \\
\text { efficacy of the vaccine in } \\
\text { persons with HIV, but } \\
\text { potential for greater benefit } \\
\text { because of high rates of } \\
\text { zoster and post-herpetic } \\
\text { neuralgia in HIV+ } \\
\text { populations. }\end{array}$ & None \\
\hline \multicolumn{4}{|c|}{ Multimorbidity and polypharmacy ${ }^{6367}$} \\
\hline & No guidelines as yet. & $\begin{array}{l}\text { May need to consider } \\
\text { multimorbidity and } \\
\text { polypharmacy at younger } \\
\text { ages than in general } \\
\text { population. Impact of these } \\
\text { conditions on HIV+ } \\
\text { individuals requires further } \\
\text { research. }\end{array}$ & $\begin{array}{l}\text { Women may be more } \\
\text { susceptible to impact of } \\
\text { polypharmacy than men - } \\
\text { requires further research. }\end{array}$ \\
\hline
\end{tabular}

Abbreviations: ART, antiretroviral therapy; $\mathrm{CBC}$, complete blood count; $\mathrm{CD} 4$, cluster of differentiation 4, also known as T-helper cells (these cells mature in the thymus); CVD, cardiovascular disease; HPV, human papillomavirus; HRT, hormone replacement therapy. 
Table 3

Website Resources

\begin{tabular}{|l|l|l|}
\hline Name of Resource & URL & Description of content \\
\hline AIDSInfo & http://aidsinfo.nih.gov/guidelines & $\begin{array}{l}\text { This site contains federally approved HIV/AIDS health care } \\
\text { practice guidelines. Of key importance are the Guidelines for the } \\
\text { Use of Antiretroviral Agents in HIV-1-Infected Adults and } \\
\text { Adolescents. Information about drug interactions can be found in } \\
\text { the tables }\end{array}$ \\
\hline $\begin{array}{l}\text { New York State Department } \\
\text { of Health, AIDS Institute }\end{array}$ & https://www.health.ny.gov/diseases/aids/ & $\begin{array}{l}\text { Excellent website containing information for patients and } \\
\text { providers. In particular, includes a number of helpful practice } \\
\text { guidelines. }\end{array}$ \\
\hline $\begin{array}{l}\text { Centers for Disease Control } \\
\text { and Prevention, HIV site }\end{array}$ & http://www.cdc.gov/hiv/ & Additional resources for patients and providers. \\
\hline FRAX & http://www.shef.ac.uk/FRAX/ & $\begin{array}{l}\text { World Health Organization fracture risk assessment tool. The } \\
\text { algorithms give the 10-year probability of hip fracture and of a } \\
\text { major osteoporotic fracture. }\end{array}$ \\
\hline
\end{tabular}

